\title{
6
}

\section{Maritime Spatial Planning and the EU's Blue Growth Policy: Past, Present and Future Perspectives}

\author{
Angela Schultz-Zehden, Barbara Weig, and Ivana Lukic
}

\section{Introduction}

Blue Growth, as a cross-cutting policy tool in Europe, has continuously evolved with the development of Maritime Spatial Planning (MSP) and several related maritime policies. The EU's overarching Integrated Maritime Policy (IMP), set in place in 2007 (EC 2012a), seeks to provide a more coherent approach to maritime issues, with increased coordination between different policy areas. In particular, it pursues three main targets: (1) sustainable development of the European maritime economy, (2) protection of the environment and (3) cooperation of all maritime players across sectors and borders.

To reach these goals, IMP suggests several tools and cross-cutting policies including Blue Growth, marine data and knowledge, integrated maritime surveillance, MSP, maritime security as well as sea-basin strategies. While the Marine Strategy Framework Directive (MSFD) stands for the environmental pillar, MSP is presented as the economic pillar (EC 2012b).

Outside Europe, MSP is often seen as a tool to ensure the needs of marine nature conservation, while also serving Blue Growth desires. MSP is therefore understood in a much broader sense as being almost more connected to the overarching IMP policy rather than the narrow understanding provided by

\footnotetext{
A. Schultz-Zehden $(\bowtie) \bullet$ B. Weig $\bullet$ I. Lukic

s.Pro sustainable projects $\mathrm{GmbH}$, Berlin, Germany

e-mail: asz@sustainable-projects.eu 
the EU Marine Spatial Planning Directive (MSPD; EC 2014c), which, however, should always be understood in context of the parallel provisions under the MSFD. As discussed in other chapters and elsewhere, under IMP, both Directives should be integrated in principle. But better coordination between all IMP cross-cutting policies has yet to be achieved in Europe (Fritz and Hanus 2015). Integration mechanisms across the EU occur at very strategic and high government levels. In many EU member states, the designated authorities in charge of the implementation of the MSPD and MSFD differ and do not want to be held responsible for each other. Thus, integration efforts may not have yet trickled down to the more practical implementation level (Ansong et al. 2018).

Moreover, some of the discussions about the role of MSP and its relationship to Blue Growth emerge from different understandings of MSP, Blue Growth or IMP — not only between European and non-European processes but also within Europe.

Therefore, in this chapter, we first shed light on the original rationale behind the Blue Growth policy in Europe and discuss its evolution. We then show how this is supported by economic figures of maritime sectors across European sea-basins and countries, including potential variations. We further explore original expectations of how MSP should contribute to promoting Blue Growth and how these have evolved as a result of projects, studies and planning processes undertaken in the meantime. We conclude with related practical implications for the work of maritime spatial planners in Europe.

Since all three policies (IMP, Blue Growth and MSP) are targeted towards all European member states, the chapter also always takes a European-wide perspective. It shows not only differences in what Blue Growth may mean across all European sea-basins but also the possible consequences for MSP processes across Europe. This is important due to the MSPD, which requires all EU member states to develop MSP plans by 2021. As a result, MSP is no longer pursued only by countries which are 'pushed' to find suitable space for offshore wind but also by those where offshore wind does not play a role.

\section{The Evolution of the Blue Growth Policy in Europe}

\subsection{The Origin of the EU Blue Growth Policy as a Way to Address the 2010 Economic Crisis}

Building upon parallel efforts on Blue Growth from the Agenda 2010 process (Barbesgaard 2016) and OECD, FAO (2014) and UNEP (2012) initiatives, 
among others, further development of the Blue Growth concept and its consequent policy in Europe can be traced back to the year 2010. The concept was highly influenced by the economic crises at the time and the need to find adequate policy responses. While acknowledging the role of global Blue Growth initiatives around the time of the global financial crisis, the focus of this chapter is on Blue Growth evolution in Europe.

The Europe 2020 Strategy suggested a way out of the economic crises by fostering smart, sustainable and inclusive growth (EC 2010). The strategy offered a vision of Europe's social market economy for the twenty-first century, by focusing on knowledge and innovation, based on the concepts of smart specialization (Foray 2015), a resource-efficient, greener and more competitive economy, and a high-employment economy-enabling economic, social and territorial cohesion (EC 2010).

Blue Growth-defined as 'smart, sustainable and inclusive economic and employment growth from the oceans, seas and coasts' (ECORYS et al. 2012: 26) — stands for the maritime pillar of the Europe 2020 strategy. In fact, the sea and the coasts have always been drivers of the European economy and centres for new ideas and innovation. In contrast to earlier times, additional new reasons, such as rapid progress in development of offshore technologies, potential for further exploration of marine resources and the relatively low emission of greenhouse gases in seaborne transport, led to the conclusion that the maritime economy could become one of the main drivers for fostering smart, sustainable and inclusive growth (EC 2012a). Whereas it was suggested that innovative approaches, new technologies and synergies would be important factors leading to a growing maritime economy, it was also argued that supporting policy measures were necessary for Blue Growth to develop to its full potential (ECORYS et al. 2012).

As discussed in the following section, the focus of the resulting EU blue growth policy has slightly changed during the last eight years, as evidenced by several development stages.

\subsection{The Development of Blue Growth and Support Approaches in the EU}

The first phase (2010-2013) of the EU Blue Growth policy was characterized by a general discussion on what is Blue Growth, how to support it and if support is needed at all. This stage was highly influenced by the initial study on Blue Growth scenarios and drivers, which analysed six maritime functions and 27 subfunctions (ECORYS et al. 2012). The study concludes that all Blue Growth activities highly depend on suitable framework conditions. Adequate 
infrastructure, high-skilled staff as well as access to low-skilled workers are as important as public acceptance, a solid international legal framework and good governance at local and regional levels (ECORYS et al. 2012). Moreover, the study concludes that blue activities differ across Europe-therefore, seabasin-specific studies and strategies should be elaborated. Due to possible heterogeneity within sea basins, it was additionally recommended to focus on specific blue clusters and develop tailor-made policy measures (ECORYS et al. 2012).

The study also analysed synergies between the 27 blue subfunctions, with emphasis on fields with a relatively high probability of cross-innovation. This was based on the claim that synergies result from shared suppliers, activities, input factors or common use of infrastructure. A focus of Blue Growth should thus be on promoting synergies, which enable the whole to be more than the sum of its parts. However, tensions between different blue activities were also identified, arising from mutually exclusive activities claiming limited space. To enable Blue Growth, it was seen as essential to avoid tensions and support the use of synergies, which could be accomplished through MSP (ECORYS et al. 2012).

Subsequently, the European Commission endorsed its Blue Growth Strategy 'Opportunities for marine and maritime sustainable growth' in September 2012 (EC 2012a). By that time, the Commission stressed that Blue Growth was sufficiently covered and supported by already existing initiatives related to MSP and Integrated Coastal Zone Management (ICZM), 'Marine Knowledge 2020', the MSFD, FP7 Ocean of Tomorrow calls and many others. The Commission actually suggested only five focus areas for policy action: (1) blue energy; (2) aquaculture; (3) maritime, coastal and cruise tourism; (4) marine mineral resources and (5) blue biotechnology. Maritime transport is left out, with reference to specific ongoing EU initiatives already in place. The Commission also emphasized that this list is not exhaustive, as new fields might emerge (EC 2012a).

On 8 October 2012, the Informal Minister Conference on Integrated Maritime Policy in Nicosia (Cyprus) approved the Limassol declaration on 'A Marine and Maritime Agenda for Growth and Jobs'. In contrast to the Commission, the ministers broadened the scope of Blue Growth actions to six priorities by also including shipping and shipbuilding, while leaving out blue biotechnology. The suggested policy actions are, however, in line with the Commission's suggestions with the main focus being laid on reducing administrative and regulatory burdens and removing bottlenecks for innovation and investment (Limassol Declaration 2012). 
The first phase of the blue growth policy ends with a resolution of the European Parliament (2013) on 'Blue Growth: Enhancing sustainable growth in the EU's marine, maritime transport and tourism sectors', which highlights in particular the role of maritime transport and tourism. The resolution addresses other aspects such as the significance of Blue Growth as part of the Europe 2020 Strategy, the importance of regional sea-basin strategies and the central role of MSP as enabler of Blue Growth. In addition, the Parliament points to the need for harmonizing planning processes at the interface between maritime and land-based planning as well as closing knowledge gaps on maritime activities (European Parliament 2013).

\subsection{Fostering Blue Growth via Stimulating Innovation in the Blue Sectors}

During the second phase (2014-2016), the discussion on Blue Growth was directed towards the topic of innovation. According to the European Commission, innovation is a prerequisite for growth and job creation, also in blue sectors. Moreover, innovation is considered to be important for improving environmental conditions. However, several studies had unveiled severe bottlenecks for innovation in Europe in general, with three barriers specific to Blue Growth: (1) gaps in marine/maritime knowledge and data; (2) diffuse research efforts hindering interdisciplinary learning; and (3) lack of scientists, engineers and skilled workers (EC 2014a).

For closing those gaps and to push aside barriers of innovation, the Commission worked out a detailed roadmap (EC 2014b). In this roadmap, the European Marine Observation and Data network (EMODnet) plays a major role for harmonizing data, standardizing access and reducing bureaucracy. EMODnet is intended to include data from diverse sources, including EU research projects, environmental studies conducted in the context of offshore wind farms (OWFs), monitoring instruments such as satellites or floating robots, as well as existing data from fisheries. The aim is to optimize observation networks by collecting data once and use them for many purposes instead of collecting data for specific purposes only. This new paradigm aims at avoiding gaps and duplications by saving costs and improving marine knowledge at the same time (EC 2014b).

The roadmap presented by the European Commission has been criticized in several aspects: a definition of blue economy is missing; lack of attention to the decline of traditional sectors such as small-scale fisheries, shipping and tourism; and consequences of the reduction of EU funds are not taken into 
account (EESC 2015). Others criticize (CoR 2015) that some of the most important blue sectors such as shipyards, shipping and blue energy are not covered in an appropriate way. A more effective matching between different EU strategies and programmes is requested as well as a specific knowledge and innovation society for blue economy to develop competences and enable better knowledge transfer from science to business. The development of entrepreneurship in blue economy should get more attention. Moreover, it should be considered that Blue Growth does not only take place on sea, but that support is also needed for blue sectors based on land, such as fish processing companies (CoR 2015).

Taking those different opinions and recommendations into account, the European Parliament endorsed its resolution on 'Untapping the potential of research and innovation in the blue economy to create jobs and growth' (European Parliament 2014). In this resolution, the Parliament emphasizes its dissatisfaction with the strict reduction of Blue Growth to five priorities and calls for a more integrative approach, including traditional and young sectors (European Parliament 2014).

\subsection{Achievements in Blue Growth Policy}

An evaluation of the Blue Growth policy in 2017 (EC 2017) comes to the conclusion that progress can so far primarily be observed in the collection of marine data and investments in research. Initiatives on skills development such as Leadership 2020 or the Commission's Blue Careers Initiative were introduced to close the gap on the labour market. Stakeholder events such as the European Maritime Day, the Blue Business and Science Forum or the Ocean Energy Forum have been established with the aim to bring together industry, finance, academia and public authorities to identify solutions and make investment more attractive. Finally, the adoption of the MSPD and the resulting need of EU member states to develop MSP as an integrative tool to improve maritime governance is noted positively, stressing the relation between MSP and Blue Growth. Weaknesses are still seen in a lack of private risk funding for innovative maritime technologies, which is still hampering maritime innovation to get to the market. Other challenges are rather sector specific (EC 2017).

In April 2017, the responsible ministers of EU member states expressed their continuous support to the Blue Growth policy (Valletta Declaration 2017). However, as already highlighted in the previous Limassol Declaration, the ministers stress again that the future direction of the Blue Growth Strategy 
should acknowledge the potential and importance of all relevant sectors of the blue economy, crucial for growth in value and jobs, and not only the five priority fields presented by the European Commission in the initial Blue Growth Strategy.

\subsection{Future Steps: The Sea Not Only as an Economic Space but Also a Political One}

In May 2017, the Committee of the Regions (CoR) offered policy recommendations, which initiated a new, third phase in the European policy on Blue Growth (CoR 2017). They request the Blue Growth Strategy to address the sea as a political topic and not only as a subject for projects. According to the CoR, the new integrated European maritime policy should provide solutions for a substantial broader set of not only economic but also sociopolitical and environmental challenges: (1) security of Europe's borders; (2) management of migration; (3) development of a maritime policy for EU's neighbourhood, regulation of maritime trade and governance of the oceans; (4) protection of biodiversity, combating climate change and successful energy transition, including transition to renewable fuels for ships; (5) development of the blue economy in traditional sectors such as fisheries, aquaculture, tourism, the maritime industries as well as emerging sectors like marine energy and marine biotechnology; (6) the reconciliation of activities and uses; (7) a coastal and maritime policy based on regions and local authorities; and (8) addressing the specific challenges of Europe's islands and overseas territories.

A coherent maritime territory is seen as the foundation of the blue economy and better interlinkage of land-and sea-based actions are fundamental to achieve this. The Committee emphasizes the importance of regional and seabasin approaches and calls for cooperation between different levels, regions and sectors. To foster investment in blue economy, regional innovation strategies (RIS3) are suggested as appropriate means. MSP as an integrative tool is expected to play a central role in implementing those ambitious ideas of this new European Blue Growth policy (CoR 2017).

On 27 June 2018, the European Commission published its first annual economic report on the EU's blue economy. This report includes a detailed definition of blue economy but avoids the use of the term 'Blue Growth'. Instead, a distinction is drawn between established and emerging sectors (EC 2018) with aquaculture included under 'established' sectors and offshore wind still included under emerging sectors. 


\section{Blue Growth: Differences Among European Sea-Basins and Countries}

\subsection{Results from the Series of Sea-Basin Blue Growth Studies}

Following the results of the initial European Blue Growth study (ECORYS et al. 2012) and variations in Blue Growth activities, as well as framework conditions between European sea-basins, a series of studies were commissioned to look into the specifics of Blue Growth sectors of EU member states around the Baltic Sea region (s.Pro 2013), the Mediterranean, Adriatic and Ionian, and Black Sea (EUNETMAR 2014), the North Sea region and English Channel (ECORYS, s.Pro, MRAG 2013), as well as Europe's Atlantic Arc (ECORYS, s.Pro, MRAG 2014).

All four studies followed the same methodological approach, identifying the largest maritime economic activities (MEAs) in terms of gross value added (GVA) and employment, as well as the fastest growing and most promising MEAs in each of the countries. While this harmonized analysis allows for comparison, it also meant that most of the data used in those studies were mainly from European-wide statistics - at that time only available for the years 2008-2010 and thus reflected an outdated picture set in midst of economic crisis. However, qualitative assessments provided in the studies-especially for identifying the most promising MEA—took into account more current expert knowledge. Nevertheless, results should mainly be understood to provide a broad picture of what may constitute Blue Growth in the various countries across Europe.

The synthesis of the sea-basin studies reveals that, not surprisingly, traditional sectors such as fishery, shipping and coastal tourism are the most important MEAs in terms of size (see Fig. 6.1) throughout all European countries. In the North Sea region also oil and gas extraction is relevant. In contract, the list of fastest-growing MEAs identified in the different countries is much longer and more heterogeneous (see Fig. 6.2). This indicates that maritime activities tend to become more diverse. At the same time, the most frequently named fastest-growing MEAs are also among the MEAs which are already the largest in terms of size. Short sea shipping, passenger ferry services and fisheries are traditional sectors, which are large and still growing. Cruise tourism is by far the most important growing sector all over Europe. In addition, at the time of the studies, a significant number of still small but rapidly growing activities emerged, such as offshore wind energy, marine mineral mining, 


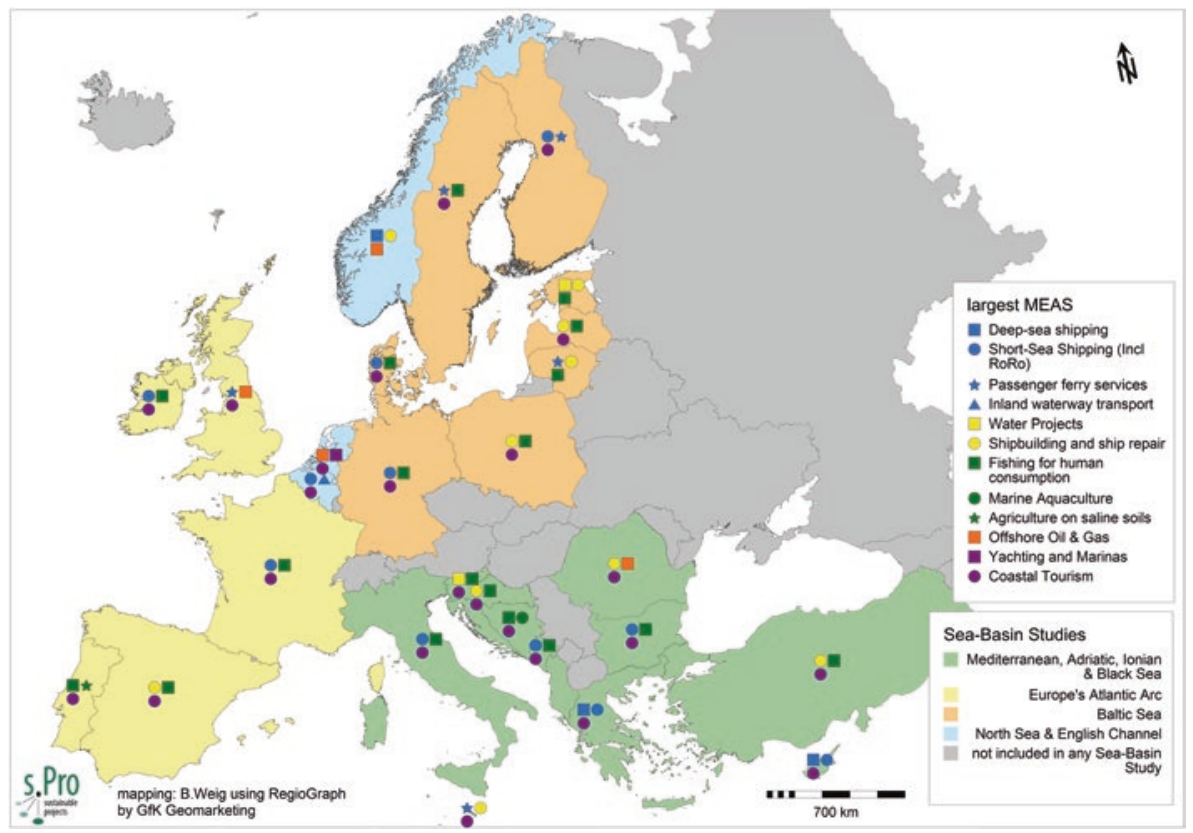

Fig. 6.1 Largest MEAs in terms of GVP and employment

fishing for animal feed, fresh water supply, protection of habitats, protection against flooding and erosion, traceability and security of goods supply chains and environmental monitoring.

The list of most promising MEAs identified for each country (see Fig. 6.3) shows even more different activities. Tourism and shipping are indicated in several countries in the Adriatic, Baltic and North Sea areas. In Portugal, Spain and France focus was placed on energy, monitoring, blue biotechnology and shipbuilding, while all forms of shipping as well as fishing were not seen as promising. In general, coastal tourism is identified in almost all countries (21 out of 28 ), followed by short sea shipping (17 countries), aquaculture (14 countries), shipbuilding (13) and offshore wind and cruise tourism (11 countries each). Whereas at the time of the studies offshore wind was only seen as fast growing in Germany and Finland, ocean energy was, however, seen as an important emerging topic in all sea basins with the exception of the Mediterranean. In contrast, there is a remarkable concentration of different growing tourism activities in the Mediterranean, especially the Adriatic Sea area.

The synthesis of the four studies demonstrates a large variety of what constitutes Blue Growth between European countries. Moreover, in most 


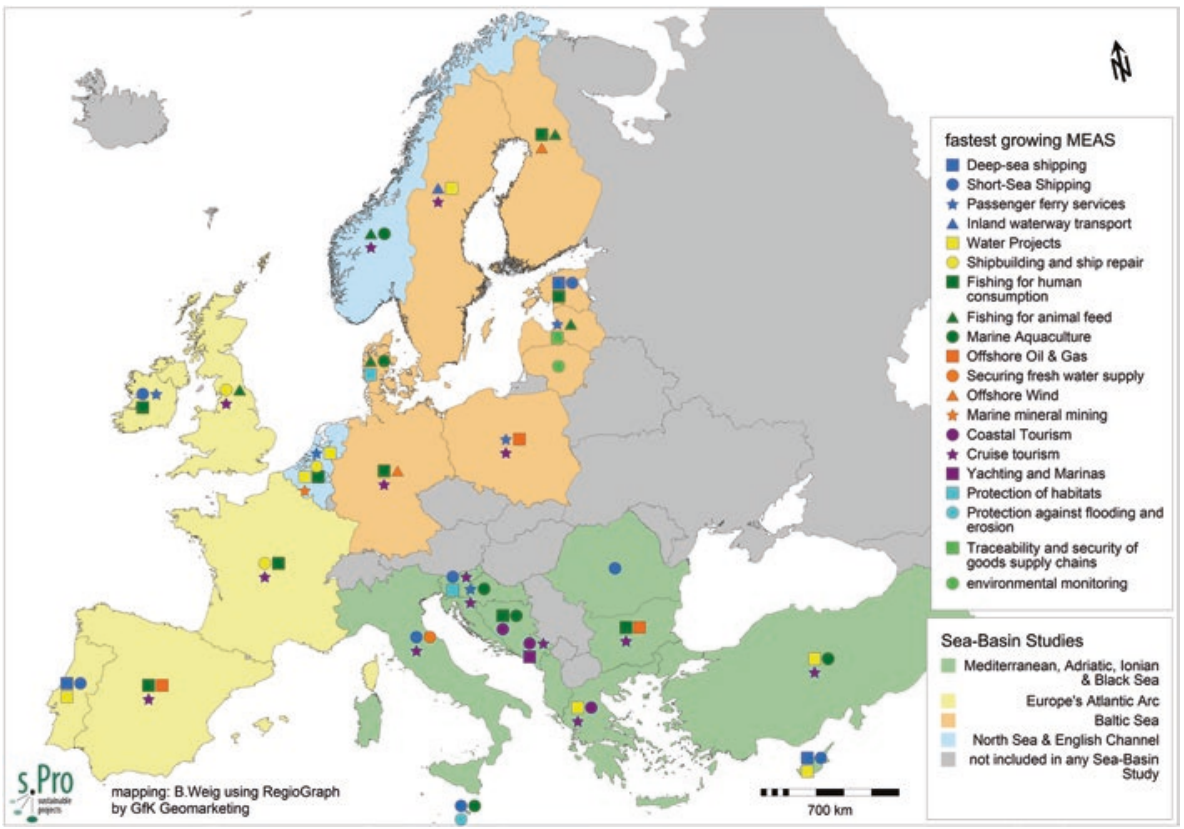

Fig. 6.2 The fastest-growing MEAs

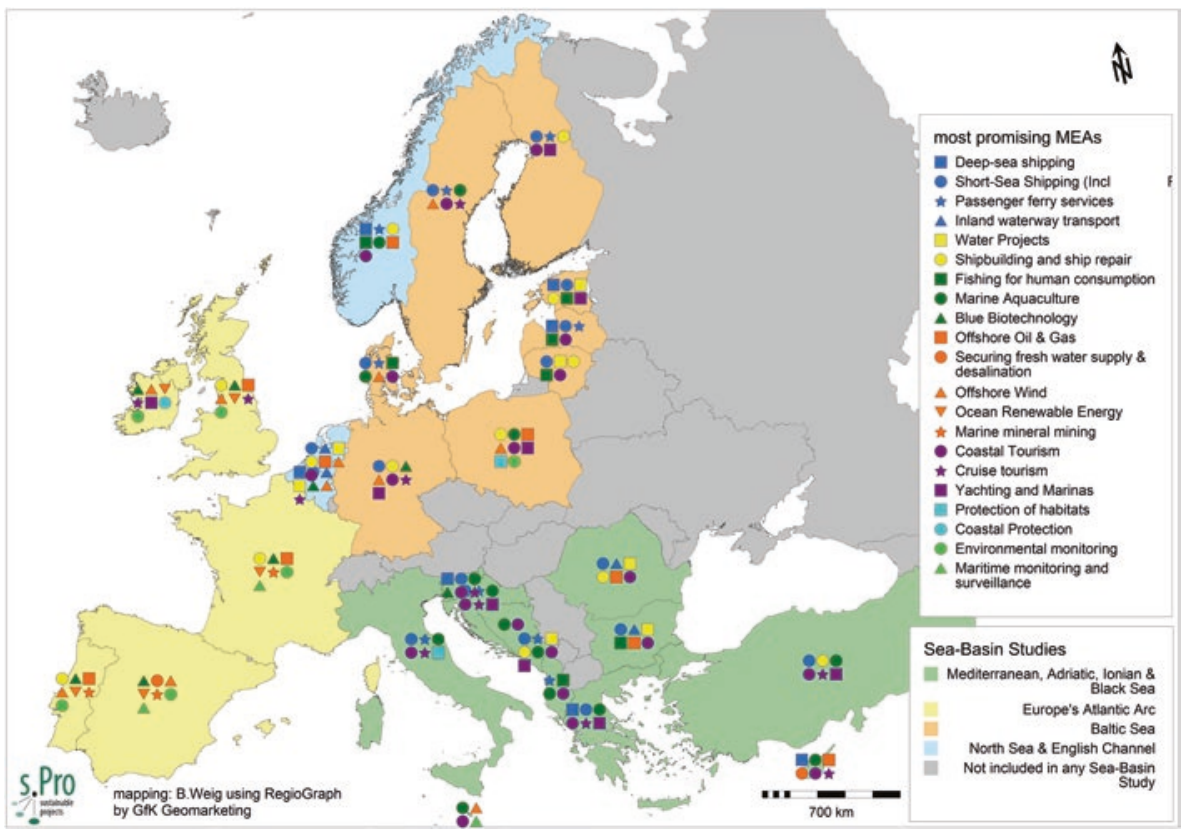

Fig. 6.3 The most promising MEAs 
countries the specific Blue Growth fields belong to different maritime functions. While the number of important sectors in terms of size was still modest at that time, the great variety of MEAs in terms of fastest-growing and most promising activities already indicated that the variety of maritime activities will probably rise. This would result in an increased need for MSP to organize a fair, secure and sustainable use of the seas.

An update of those studies has just been published by the European Commission (EC 2018), which confirms most of the assumptions made in the earlier studies. For reasons of data availability, the report focuses on monitoring the development of the established blue sectors (including fisheries, shipping, tourism as well as aquaculture). It comes to the conclusion that these traditional sectors developed positively from 2009 to 2016. Employment rose by $2 \%$, while average wages increased by as much as $14.2 \%$ (EC 2018). In 2016, the GVA of those established blue sectors was $9.7 \%$ higher than in 2009, while net investment in tangible goods increased by $71.7 \%$. However, the sectors developed differently during and after the years of economic crises. While sectors in the field of living resources (fisheries and aquaculture and processing and retail) and coastal tourism increased in terms of GVA and employment, other sectors such as shipbuilding and repair as well as oil and gas extraction suffered losses (EC 2018). Much of this was foreseen in the earlier studies. Most emerging sectors still lack sufficient data for detailed monitoring. The offshore wind sector is an exception: this sector has grown most rapidly with the number of jobs rising from 20,000 in 2009 to 160,000 jobs in 2016 . A total of $91 \%$ of the global capacity in terms of gigawatt is located within the EU, with potential for further growth (EC 2018).

In addition, the MUSES (Multi-Use in European Seas) project (Przedrzymirska et al. 2018) has provided a comparison of possible maritime multi-uses across the different European sea-basins. Even though this study is not based on economic data per sector in each country, it sheds an interesting light on the substantial differences between sea basins. This difference is especially prominent between Northern and Southern European countries, where different blue sectors appear to constitute a main driver for the respective national economies. Offshore wind and other renewable ocean energy sources are still the main driver for Blue Growth policy throughout Northern Europe. In contrast, most initiatives in Southern European sea-basins (Atlantic, Mediterranean and Black Sea) focus on smart combinations of new and old maritime economic sectors with tourism, which constitutes the primary expanding income source for those countries. The absence of a strong push for offshore wind development in the Southern European countries has 
substantial implications on what type of Blue Growth Policy should be emphasized and what may be key objectives and strategic goals for MSPs in those countries.

\subsection{Blue Growth Policy: Supporting All Sectors or Only a Few?}

As shown from the analysis earlier, a clear definition of what is exactly covered and understood under the European Blue Growth concept is currently still missing. So far, two different understandings compete in official documents. The comprehensive understanding of Blue Growth includes all maritime activities, as well as cross-sector activities and their respective land-based activities. However, the narrow approach so far supported by the European Commission understands Blue Growth as a support tool for young but high growth potential sectors, thus reducing Blue Growth to five sectors. Even though the European Parliament, the European Economic and Social Committee, the Committee of the Regions and others repeatedly propose using the comprehensive approach, the European Commission has so far always come back to the five focus areas, whenever dealing with Blue Growth (EC 2012a, 2014a, 2017).

Taking into account the significant variation among European countries concerning important blue growth activities, and also acknowledging that in most sea basins the five focus areas stressed by the European Commission only play a minor role, a suggested best way forward is to embrace a broader approach of Blue Growth and an accompanying strategy. These should be flexible enough to take into account regional and sectoral characteristics and needs - combined with a profound IMP and readiness for future challenges. Such an inclusive definition would also help to raise awareness of the importance of our seas among a broader range of stakeholders, which in turn is needed to make full use of its potential.

This is also confirmed by the MUSES 'Action Plan' process, which is based on the analysis of possible and promising multi-use concepts throughout European sea-basins (Lukic et al. 2018). The action plan shows that, apart from the need to push for technology breakthroughs for suitable multi-use combinations with offshore energy installations in Northern European countries, embracing cross-sectoral synergies and employing new technologies (also in traditional, developed or even declining sectors) provide totally new opportunities for sustainable Blue Growth in areas where this was previously not expected. The report emphasizes the importance of such multi-use 
concepts not only for Southern European countries but also for enabling Blue Growth in rural areas and remote island communities throughout the whole of Europe.

For example, pescatourism, an activity that combines fishing and tourism, allows artisanal fishers to diversify their activities and ensure an alternative source of income (Castellani et al. 2017; Vergílio et al. 2017). Also, the identification of multi-use opportunities between underwater cultural heritage (UCH) sites and tourism activities allows for new activities such as diving trails in UCH sites or virtual UCH tours on land. These may provide important sources of funding for $\mathrm{UCH}$ or nature protection sites while diversifying tourism offers (Przedrzymirska et al. 2018). These Blue Growth opportunities require policy actions focusing on capacity building of local stakeholders involved. This is quite different from the actions targeted towards the energy sector, which depend on an initial high level and advanced capacity (Lukic et al. 2018).

\section{The Role of MSP in the EU Blue Growth Policy}

\subsection{Blue Growth Policy: More than MSP}

As shown earlier, from the very beginning of the emergence of the Blue Growth concept, MSP has been mentioned as an important enabling tool which provides the precondition for maritime activities to thrive. However, as the discussion also demonstrates, MSP is by no means the only and most important policy tool to promote Blue Growth in Europe.

Other tools and support actions, which are not directly under the remit of MSP, are equally_ if not even more-important and necessary to address the most urgent current challenges and thus foster the development of the various maritime sectors: (1) regulations, which are important for legal security of blue activities; (2) promotion programmes which foster knowledge transfer from research to business and thus accelerate technology innovations; (3) maritime skills development and training programmes to provide for the skilled labour forces necessary to apply new technologies; (4) efforts to gain better and relevant data and information; (5) initiatives which facilitate and streamline investments including risk funding for innovative maritime technologies; (6) economic support policies, programmes, incentives; and (7) facilitation of events and forums, which bring together industry, finance, 
academia and public authorities to come to joint solutions. These are just a few of the main actions necessary.

Although not completely representative, this more 'balanced' view on MSP was also confirmed during the interviews undertaken within the framework of the 2013 Baltic Sea Blue Growth study (s.Pro 2013). Of all four IMP areas, MSP was seen as least important by EUSBSR (EU Strategy for the Baltic Sea Region) stakeholders at that time. Additionally, the resulting European Commission working paper towards 'A sustainable Blue Growth Agenda for the Baltic Sea Region' (s.Pro 2017) puts more emphasis on (1) a consistent approach to innovation; (2) skills and qualifications; (3) cluster development; and (4) access to finance for maritime sectors. The follow-up stakeholder process undertaken four years later to promote the implementation of the Baltic Blue Growth Agenda (s.Pro 2017) confirms this by stressing the need to 'remove regulatory barriers', 'foster issue-driven collaboration' as well as increased efforts to 'raise awareness for blue products'.

\subsection{Assumed Benefits of MSP to Blue Growth}

Nevertheless, the role of MSP as an important facilitator and enabler for fostering the development of maritime sectors should also not be underestimated. A pre-impact study commissioned by the European Commission in the wake of the introduction of the MSPD (EC 2014c) pointed to the following three main economic effects of MSP:

1. MSP was anticipated to result in higher efficiency and therefore cost reductions for governments due to enhanced coordination, integrated decisionmaking and simplified decision processes. Whereas the initial set-up of an integrated and aligned MSP process would involve additional costs, these should ultimately lead to overall cost reductions in the long run due to lower administrative, employment and overhead costs per procedure or activity of governmental bodies working in the maritime field.

2. Proper MSP was also seen to lead to reduced transaction costs for industry across the following four dimensions:

- In view of the common knowledge base created through MSP processes, individual businesses would likely have less search costs in relation to finding the right location, where their maritime activity can take place.

- MSP was also foreseen to create substantial savings in legal costs, that is, those costs which occur due to determining that a business action is legitimate and in compliance with agreements. 
- Also with regard to businesses, administrative costs deriving from application and approval processes for permits, licenses and certification would be reduced, assuming that MSP would lead to more efficient and aligned decision procedures of the various government authorities involved.

- MSP should also reduce business costs in order to reduce conflicts with existing or emerging maritime activities in the given space or impacted by the use. MSP should enable governments to incorporate interests of stakeholders and thus prevent such conflicts to happen in the first place.

3. Lastly, due to the enhanced legal certainty and security provided through maritime spatial plans, in particular, spatial allocations for each maritime sector, the general investment climate for the blue economy was foreseen to improve-meaning that investors would increase and accelerate investments into established as well as new blue sectors.

This basic set of positive effects of MSP on stimulating Blue Growth was confirmed by a later study undertaken by the World Ocean Council (WOC 2016). Even though described in different terms, the paper presents the same potential benefits of an integrated MSP approach to ocean industries and thus the overall economy. This is remarkable as the information basis of that paper differed substantially from the earlier study undertaken on behalf of the European Commission. Instead of predominantly relying on government authorities from across Europe, the WOC included also input from the ocean industry itself and non-European sources (mainly from US and Australia) in addition to European cases (e.g. Norway, Germany and the UK East Inshore Plan).

\subsection{Assumptions and Concerns on MSP Processes}

The WOC paper, however, also pointed to some limits and concerns, which were voiced by the private sector regarding MSP. These mainly referred to the fact that MSP can only act as a Blue Growth facilitator if the process leading to an agreed plan is carried out properly:

- Whereas MSP may ultimately lead to streamlined processes, industry was concerned that its introduction would initially lead to uncertainty, delay and thus negative economic effects for business and communities.

- Many economic benefits associated were only associated with statutory, legally binding MSP processes, as opposed to non-legally binding or pilot MSP processes. 
- Some industry sectors claimed that conflict resolution is only required for coastal, shallow areas, which is in high demand by many diverse users. They therefore questioned the need for MSP processes for offshore areas, where little conflicts occur and thus initial costs associated with an MSP process may not be outweighed by potential benefits.

- Furthermore, industry voiced concern on whether MSP processes can really be designed in such a way to allow them to adequately participate in the development and design of the MSP, which is in turn, however, a precondition to generate the economic benefits of an MSP process. Most stakeholders understood that MSP may not always end in a 'win-win' situation with all user needs accommodated in every location. It was, however, seen as necessary that all uses and resources are considered simultaneously and that this needs to remain a dynamic process in view of emerging and future uses.

- Moreover, there was concern whether current MSP processes have sufficient tools available to quantify and evaluate trade-offs among competing uses, users and finite resources, and thus accurately determine positive and negative consequences of a plan.

- Benefits associated with an increased knowledge base were only seen as possible if planning processes were to disclose the source and methodology used.

Within Europe, most of these process principles were already defined in 2008 by the European Commission in the 'Roadmap on Maritime Spatial Planning'; most of which are reflected in the 'Minimum Requirements' as stipulated by the EU MSPD:

\begin{tabular}{|c|c|}
\hline$U R$ & Requ \\
\hline $\begin{array}{l}\text { P according to area and } \\
\text { f activity } \\
\text { objectives to guide MSP } \\
\text { p MSP in a transparent } \\
\text { age stakeholder } \\
\text { pation } \\
\text { nate within member } \\
\text {-simplify decision processes } \\
\text { legal effect of national MSP } \\
\text { nent cross-border } \\
\text { ation and consultation } \\
\text { orate monitoring and } \\
\text { tion in planning process } \\
\text { e coherence between } \\
\text { rial and MSP-relation with } \\
\text { a strong data and }\end{array}$ & $\begin{array}{l}\text { shall } \\
\text { account land-sea } \\
\text { acco } \\
\text { account environmental, } \\
\text { pects; } \\
\text { omote coherence between } \\
\text { the resulting plan or plans } \\
\text { r processes, such as ICZM or } \\
\text { t formal or informal } \\
\text { le involvement of }\end{array}$ \\
\hline
\end{tabular}




\section{How to Implement MSP as to Lead to Blue Growth}

\subsection{MSP Projects and the MSP Platform Supporting EU MSP Implementation}

As shown earlier (EC 2011), the adoption of the EU MSPD in 2014 marks a milestone also for Blue Growth as it obliges all coastal EU member states to have MSPs in place by 2021. The question on whether MSP has a positive effect on the blue economy is, however, highly dependent on how member states actually implement MSP and thus bring the key principles of the MSP Roadmap into life.

In order to assist EU member states in the implementation of the EU MSPD, the European Commission is continuously providing funding for MSP-related projects. Moreover, since early 2016, the so-called European MSP Platform facilitates European-wide knowledge exchange and generation of MSP implementation practices.

As part of the service, the study 'MSP for Blue Growth' (s.Pro, ECORYS 2018) examined different projects, practices, approaches and lessons learnt that may help EU member states render their MSP processes more effective in developing sustainable Blue Growth. The study is less focused on providing evidence on whether or not MSP can be seen as a key tool for achieving sustainable Blue Growth, but is rather designed to provide practical guidance to maritime spatial planners as well as related stakeholders on how to realize this. Specifically, it covers the following related aspects: (1) How to develop visions that can be effectively used in MSP? (2) What kind of future trends impact sector development and how do they influence the MSP process? (3) How can MSP authorities monitor whether they are on the right track with the Blue Growth objectives of their MSPs?

\subsection{Guidance on How to Take Sector Considerations on Board}

MSP projects especially in the Baltic Sea such as the BaltSeaPlan Vision 2030, PartiSEApate, BaltSpace, Baltic SCOPE and Baltic LINes (Varjopuro et al. 2015) as well as some EU-wide research projects (esp. with focus on aquaculture; i.e. AquaSpace, Co-Exist) (s.Pro, msp-platform, 2018) have started to look into sector-specific aspects that maritime spatial planners should take into account to enable sustainable Blue Growth. Most notably, 
the PartiSEApate project was the first ever MSP project, which systematically reached out to sector stakeholders to initiate a pan-Baltic dialogue on how best to integrate them into MSP processes both at national and at transnational level (Schultz-Zehden and Gee 2015). Moreover, the project provided key recommendations on the future Baltic Sea-wide MSP governance system suggesting among others to build much closer links with the existing transnational sector-specific organizations (Schultz-Zehden and Gee 2016).

The 'MSP for Blue Growth' study is, however, the first initiative which has comprehensively assessed this for all nine key maritime sectors across the whole of Europe. The resulting sector fiches not only provide information on the current nature of spatial requirements of the various sectors but also consider the implications of future developments and their consequences for sector requirements in a given maritime space, as well as offering concrete recommendations on how both planners and sectors may inform each other to create suitable MSP solutions which unlock the respective Blue Growth potentials in a sustainable manner.

The following paragraphs provide for a snapshot of the main factors planners have to consider in relation to the various sectors at stake.

\section{The Traditional, Big Sectors}

\section{Shipping: Maritime Spatial Planning Important Role}

While shipping is guided by freedom of navigation and thus allowed everywhere, MSP is highly important for ensuring that important routes are kept free as shipping is in conflict with all fixed installations. Nevertheless, most MSP initiatives have found it difficult to involve the sector.

Most MSP processes start off with existing IMO shipping routes. Even though these can be changed in principle and in some instances have also been earmarked as useful to be shifted, for example, due to environmental considerations, such changes are a lengthy process. Thus, first-generation MSPs normally have to take existing IMO routes as a 'given'.

The actual size of the free shipping lane depends on traffic volume and size of ships: The higher the traffic volume and the bigger the ships, the wider and deeper the free shipping lane needs to be. In addition, increased emergence of weather extremes requires availability of space to which ships can deviate to avoid bad weather. 
Data and information on current ship traffic patterns are continuously improving but are not always easily accessible and need a lot of processing capacity. Moreover, MSP processes need to anticipate future shipping routes. In doing so, planners have to have information on future port developments: Which of them will accommodate the larger ships? What are the land connections and who do they service? Are there new ports upcoming, which may influence shipping routes?

Also other new ship traffic routes are expected to emerge in view of ship maintenance, short sea shipping and recreational as well as tourism-oriented shipping. These routes follow completely different patterns. The spatial implications of autonomous vessels are not yet clear, but in the near future, there is a need to allocate separate, exclusive test beds free of other uses.

Planning approaches currently differ between countries: some take a maximum approach taking into account also future port developments. Others rather take a minimum approach by focusing on the most important routes and those areas, which ships need to avoid.

\section{Fishery: Maritime Spatial Planning to Be Integrated into Overall Fisheries Policy}

Similar to shipping, fishing has a long tradition of claiming space and has not been easy to integrate into MSP processes, as those are often understood to take space away, while not being able to provide the necessary spatial security. In fact, currently most plans only consider fishing, when allocating space to other uses, but do not allocate specific areas to fishery.

Planners are in need of much better information and tools, which enable them to better consider relevant areas for fishing and fish species according to life stages (incl. spawning areas). Similar to shipping, continuous improvements are, however, made, for example, in Vessel Monitoring System (VMS) and Automatic Identification System (AIS) data systems and models, which will facilitate planning in the future.

But at the same time, MSP is by no means the only instrument for fisheries management. Maritime spatial planners have no influence, for example, on fish quota, meaning that in case of closure of some areas more fishing is taking place in less space. Thus, interaction between MSP and the sector should take place at a much earlier stage, in order to provide for better linkage and integration of MSP into the overall evolvement of fisheries policy, including cross-border considerations. 
Coastal and Maritime Tourism: Maritime Spatial Planning Indirect, but Important Role

Continuous growth of coastal and cruise tourism and the related infrastructure developments and subsequent impacts have implications on MSP decisions and vice versa. These land-sea interactions are highly important and a good interlinkage between maritime and terrestrial planning including efficient multi-level governance is crucial. Moreover, MSP processes and authorities may play an important role in fostering synergies between maritime uses, which are beneficial for tourism.

Appropriate assessment tools are only slowly evolving, but more and more research efforts are undertaken to foster a better understanding also on concepts such as cultural landscapes; recreational values and attractive living areas, which are closely connected.

\section{Ocean Energy Sectors}

\section{Offshore Wind: Maritime Spatial Planning Important Direct Role (but Sector not Relevant for Some Sea-Basins)}

As evidenced before, the sector shows continued growth and thus growing demand for space in many Northern EU countries and is expected to emerge also in numerous countries where currently no offshore wind is in place. However, this is less likely in Southern Europe.

The sector is also important in view of long-time impacts of spatial decisions. Once installed, the infrastructure remains in place for a long time with considerable implications for other maritime uses.

MSP considerations differ depending on the method for designation of OWF zones. Some governments allocate specific sites for OWF development and thus also cover for the Environmental Impact Assessment (EIA) and related grid connections. This method is a valuable tool for large-scale deployment in short term. In case of an open door policy, large zones are designated as search areas for industry, with more responsibility on their side to conduct the EIA and organize the grid connections. Such an approach is more prone to foster innovative, market-based blue energy solutions.

Moreover, MSP authorities play an important role in decisions on whether OWF areas are open or closed to other uses such as fishery, aquaculture, recreation/tourism purposes as well as conservation needs. They are also in charge of the Strategic Environmental Assessments (SEAs), which in turn should 
facilitate EIAs. Better SEAs and more multi-use options may decrease resistance to new developments.

At the same time, technological advances may have substantial spatial implications. The emergence of floating wind farms, possible connections of OWF to interconnectors and new energy storage systems open up new potential sites especially further offshore and substantially influence the related environmental impacts.

\section{Cables and Pipelines: Maritime Spatial Planning Important Direct Role (Long Time Horizon)}

The installation of new submarine cables and pipelines has to be taken into account by MSP in view of the potential for more efficient use of space by bundling corridors for electricity and telecom cables and pipelines, while also considering the related increased risk factor in case of damage.

Grids and interconnectors are important in facilitating more ambitious energy system scenarios and improved routing and installation criteria can lead to avoidance of conflicts, for example, with fishing. There is potential to facilitate better siting due to improvements in submarine 3D bathymetric mapping. At the same time, it should be noted that often general data is missing and that, in some cases, MSP authorities are not always in charge of the detailed planning of related routes.

\section{Tidal and Wave: Maritime Spatial Planning May Facilitate Development}

The sector is only relevant in the North Sea and the Atlantic Ocean. It is important to consider synergies with offshore wind energy infrastructure including vessels, grids, cables as well as onshore transmission. MSP requires accurate resource mapping of tidal and wave power potential to be able to locate areas of interest.

\section{Oil and Gas: Maritime Spatial Planning Should Only 'Consider' the Sector}

The sector is only relevant in a few EU countries, and new sites are only foreseen in very limited cases. Thus for MSP and its role in Blue Growth, it is mainly important to integrate the current sites (also those to be decommissioned) and the related maritime activities in light of creating synergies with other uses. 


\section{Other Place-Based Maritime Sectors}

\section{Marine Aquaculture: Maritime Spatial Planning Can Foster Sector, but Depends on Sector Input and Actions}

MSP has a potentially important role in fostering the development of marine aquaculture, but this has to be done in strong cooperation with other Blue Growth policy areas as the sector itself is not strong enough to provide the necessary push.

Whereas visual and physical impacts of marine aquaculture may be similar regardless of which type and species cultured, feasible environmental condition requirements as well as vice versa environmental impacts of the given aquaculture vary substantially between the different forms of aquaculture (e.g. shellfish, seaweed, fish) as well as between the different species.

Planners and the sector should work together to identify new and better areas for aquaculture potential. MSP may support the sector by providing better and open access to relevant data, which is are otherwise not available to small individual aquaculture companies.

Moreover, MSP can stimulate the creation of clusters of farms by allocating aquaculture zones. So far, the small-sized aquaculture companies tend to prioritizes coastal space, even though offshore areas may substantially increase social acceptance and reduce conflict fields with other uses.

\section{Marine Aggregates and Mining: Maritime Spatial Planning Important Direct Role}

There is increasing demand for dredging sites for sand and gravel with spatial allocation depending on the resource. Dredging is necessary due to coastal defence and protection but may, at the same time, itself have substantial environmental impacts. It is important to follow technology developments which may improve sustainability.

Actual dredging only requires limited areas, but it is important that the seabed at these locations is not negatively impacted by other sectors (known as mineral safeguarding). Planning has to consider not only the actual locations but their surroundings. Moreover, industry investments have a much longer time horizon (30 years) than MSP; thus also future revisions of MSPs need to safeguard these time horizons.

Contrary to general belief, there is, however, potential for combinations with numerous other sectors, especially in light of the temporal aspect of when the actual dredging is carried out, but better evidence is required. 


\section{Summary}

Taken together, the sector fiches show the large diversity of the spatial characteristics and time horizons of the various sectors. Whereas it has been commonly assumed that MSP is specifically important for supporting suitable siting of emerging place-based industries in ocean energy (especially offshore wind and increasingly the related cables and pipelines), the fiches also show the role of well-informed MSP for ensuring the ongoing development and evolution of traditional activities such as shipping, fishery and tourism.

The sector analysis highlights the importance of aligning MSP processes with other related Blue Growth policies and the need for much closer cooperation with sectors at an early stage of planning. Rather than seeing MSP as an isolated task, the study indicates that MSP processes and the work of individual sector organizations, such as Regional Fisheries Advisory Councils, should be better aligned. For other sectors, the study describes the limited impact of MSP, such as on aquaculture development, unless there is a much stronger connection created at an early planning stage to allow for better input by the sector itself to indicate optimal sites. Moreover, it underlines the importance of a much stronger merging, not only of maritime and terrestrial spatial planning but the overarching regional development programmes especially in view of tourism and port development (EC 2018).

These are just a few of the useful study insights, in light of the increasing number of MSPs being developed in the coming years in countries with no offshore wind or other renewable energy industries acting as main drivers. Therefore, Blue Growth is foreseen to be generated by other maritime sectors in those countries (EC 2018).

\subsection{MSP for Blue Growth Is About Strategic Planning for the Future}

The study also underlines the importance of interlinking MSP processes with the development of maritime visions and strategies (EC 2018). The earlier MSP economic impact studies mainly emphasize the ability of MSP to reduce or avoid conflicts among sectors, which occur most often in coastal, shallow areas (World Ocean Council 2016). This fact however neglects the more strategic planning function of MSP processes and resulting plans in terms of promoting Blue Growth.

In that sense, MSPs should no longer only be developed in reaction to pressure from already existing strong industry demands, nor should MSP be 
limited to the function of minimizing current conflicts or preventing such conflicts to happen in the future. It is actually more of a tool to put the maritime space on the 'economic' agenda by showing the sustainable development potential of the sea to inspire new stakeholders to take advantage of that Blue Growth potential and to find the right place to do so. With that understanding, MSP can also be of high Blue Growth relevance for less crowded sea areas, as it may show optimal, new areas for certain maritime activities. By focusing in parallel on (terrestrial) areas in need of economic development, MSP can thus inspire relevant initiatives in other policy fields (i.e. food security, cohesion policy). It was in this spirit that the first Lithuanian MSP was developed (Schultz-Zehden and Gee 2013).

The EU MSPD does not oblige EU member states to develop a maritime vision or strategy as part of the MSP process. Nevertheless, numerous countries (e.g. Belgium, the Netherlands, Sweden) have opted for a broader understanding of their MSP process by combining it with a vision or strategy development processes.

As shown in the MSP for Blue Growth study (s.Pro and ECORYS 2018), vision processes are an important tool to promote collaboration between sectors and stakeholders-who may currently experience tensions-by instigating a dialogue on a positive, joint future to work towards. Vision processes are also useful, in that they draw attention to uses, which are not present so far, as well as other emerging issues (such as climate change or other broader demographic, political or economic developments). Moreover, the future development of some sectors, such as ocean energy and marine aggregates, depends on a long-term framework providing stable locations. Planning periods of these sectors go well beyond the typical six-year horizon of the MSP, and the resulting structures can remain fixed for decades. Therefore, the development of a long-term maritime vision or a strategy has an important role to provide certainty for these sectors, which exceeds political cycles and may even provide the basis to derive smart objectives for the given MSP process. The task of the MSP is consequently to link this desired future to present conditions and related spatial planning needs.

Currently, however, hardly any MSP process has a systematic monitoring and evaluation framework in place, which not only requires to set objectives but also translate them into measurable targets against current baselines (MSP for Blue Growth study: Indicator Handbook, s.Pro and ECORYS 2018). Moreover, there is the urgent need to develop and introduce tools to be able to carry out a more systematic cost-benefit analysis of the provisions of a draft maritime spatial plan, for example, assessing costs of a rerouting of shipping set against the benefits of avoiding a sensitive area (Jay 2017). 


\section{Conclusions}

\subsection{MSP as Part of the Overarching Framework of an Integrated Maritime Policy}

MSP is a powerful tool for Blue Growth, but it can only realize its full potential by being strongly interconnected not only with the whole set of other Blue Growth measures but also as part of the overarching framework of an IMP. For example, development of maritime visions and strategies as part of an MSP process may function not only as a preparatory step for MSP but also provide a long-term overarching framework for an IMP. Such vision can also serve to address wider national priorities and link MSP to other planning frameworks, including integrated coastal zone management, territorial development planning, and other relevant policies including food security, research and innovation or cohesion policy.

\subsection{MSP Is About Planning for the Future}

MSP is not only about reducing current conflicts but also about providing a vision for the sea as a source of sustainable national development. It has an important Blue Growth function not only for coastal areas but also by putting the open maritime space onto the economic agenda. MSP, if orchestrated and aligned with other policy tools, has the power to initiate Blue Growth also in currently still unused sea areas and showing the whole maritime space as a development field. On this premise, MSP processes should consider rural development areas while at the same time providing indication of potential strategic resource areas where traditional and new offshore technologies and uses can be developed.

\subsection{Blue Growth Potential Is Reaching Beyond Five Key Sectors}

While development in key Blue Growth sectors can satisfy high-level policy goals and bring prosperity over the long run, local coastal communities very much depend on traditional uses for their day-to-day livelihoods. Therefore, the scope of Blue Growth policies should also take into consideration potential for growth in traditional sectors through innovation and implementation of multi-use concepts and sector combinations. MSP in countries where there 
is no 'push' from Blue Growth sectors such as ocean energy may orient towards Blue Growth through diversification of traditional sectors such as fisheries and tourism. Moreover, cooperation with sectors such as fishing, aquaculture as well as tourism has to start at a much earlier pre-planning stage to integrate MSP with sector policies.

In countries with present key Blue Growth sectors, taking this wider approach to Blue Growth and considering cross-sectoral synergies can ensure a more sustainable integration of new and emerging sectors into existing contexts and more local socio-economic benefits.

\subsection{Integration Through MSP and of MSP}

MSP is not only an important tool to support emerging sectors but also key to secure the traditional, more mature sectors such as shipping, fishing and tourism. Realizing that Blue Growth potential lies not only in the given five key sectors originally associated with Blue Growth, and that MSP can integrate a wider set of maritime policies, allows for addressing a much wider set of challenges and unlocking a larger future development potential. For this to happen, it should, however, be understood that MSP may not only act as the integrative tool, but that MSP should also integrate itself much earlier into the overarching as well as sector-specific Blue Growth policies both at EU and at national level.

Acknowledgements We are grateful to the project 'Economy of maritime space' funded by the Polish National Science Centre for contributing the Open Access fee for this chapter and facilitating our discussions and preparation of the book.

\section{References}

Ansong, J., O'Hagan, A. M., \& MacMahon, E. (2018). Existing Mechanisms for Cooperation on MSP in the Celtic Seas (Deliverable 14). EU Project Grant No.: EASME/EMFF/2014/1.2.1.5/3/SI2.719473 MSP Lot 3. Supporting Implementation of Maritime Spatial Planning in the Celtic Seas (SIMCelt) (pp. 74). University College Cork.

Barbesgaard, M. (2016). Blue Growth: Saviour or Ocean Grabbing?. An International Colloquium Global Governance/Politics, Climate Justice \& Agrarian/Social Justice: Linkages and Challenges. Colloquium Paper No. 5. Retrieved from https://www. tni.org/files/publication-downloads/18-icas_cp_doerr.pdf. 
Castellani, C., Carrer, S., Bocci, M., Ramieri, E., Depellegrin, D., Venier, C., Sarretta, A., \& Barbanti, A. (2017). Case Study 6: Coastal and Maritime Tourism and O\&G Decommissioning as Drivers for Multi-Use in the Northern Adriatic Sea. MUSES Deliverable: D3.3-Case Study Implementation-Annex 9. MUSES Project.

CoR. (2015). Opinion of the Committee of the Regions-Innovation in the Blue Economy: Realising the Potential of Our Seas and Oceans for Jobs and Growth (2015/C 019/05).

CoR. (2017). Opinion of the European Committee of the Regions on 'A New Stage in the European Policy on Blue Growth (2017/C 306/11).

ECORYS, et al. (2012). Blue Growth-Scenarios and Drivers for Sustainable Growth from the Oceans, Seas and Coasts. Final Report. Commissioned by DG. MARE. Retrieved from https://webgate.ec.europa.eu/maritimeforum/system/files/Blue\%20Growth\%20Final\%20Report\%2013092012.pdf.

ECORYS, s.Pro, MRAG. (2013). Study on Blue Growth and Maritime Policy Within the EUNorth Sea Region and the English Channel. Final Report FWCMARE/2012/06SC E1/2012/01. (Conducted for DG Maritime Affairs and Fisheries).

ECORYS, s.Pro, MRAG. (2014). Study on Deepening Understanding of Potential Blue Growth in the EU Member States on Europe's Atlantic Arc. Final Report FWC MARE/2012/06-SC C1/2013/02. (Conducted for DG Maritime Affairs and Fisheries).

EESC. (2015). Opinion of the European Economic and Social Committee on the 'Communication from the Commission to the European Parliament, the Council, the European Economic and Social Committee and the Committee of the Regions-Innovation in the Blue Economy: Realising the Potential of Our Seas and Oceans for Jobs and Growth' (2015/C 012/15).

EUNETMAR. (2014). Studies to Support the Development of Sea Basin Cooperation in the Mediterranean, Adriatic and Ionian, and Black Sea. Final Report FWC MARE/2012/07-Ref. No 2. (Conducted for DG Maritime Affairs and Fisheries).

EC. (2010). Europe 2020-A Strategy for Smart, Sustainable and Inclusive Growth (COM(2010) 2020).

EC. (2011). Study on the Economic Effects of Maritime Spatial Planning. Final Report. Retrieved from https://ec.europa.eu/maritimeaffairs/sites/maritimeaffairs/files/docs/body/economic_effects_maritime_spatial_planning_ en.pdf.

EC. (2012a). Blue Growth Opportunities for Marine and Maritime Sustainable Growth $(\mathrm{COM}(2012) 494$ final).

EC. (2012b). Progress of the EU's Integrated Maritime Policy (COM(2012) 491 final).

EC. (2014a). Innovation in the Blue Economy: Realising the Potential of Our Seas and Oceans for Jobs and Growth (COM(2014) 254 final/2).

EC. (2014b). Marine Knowledge 2020: Roadmap (SWD(2014) 149 final).

EC. (2014c). Directive 2014/89/EU of the European Parliament and of the Council of 23 July 2014 Establishing a Framework for Maritime Spatial Planning. 
EC. (2017). Report on the Blue Growth Strategy Towards More Sustainable Growth and Jobs in the Blue Economy (SWD (2017) 128 final).

EC. (2018). The 2018 Annual Economic Report on EU Blue Economy. Retrieved July 2, 2018, from https://ec.europa.eu/maritimeaffairs/sites/maritimeaffairs/ files/2018-annual-economic-report-on-blue-economy_en.pdf.

European Parliament. (2013). Blue Growth-Enhancing Sustainable Growth in the Marine, Maritime Transport and Tourism Sectors (2012/2297(INI)).

European Parliament. (2014). Research and Innovation in the Blue Economy to Create Jobs and Growth European Parliament Resolution of 8 September 2015 on Untapping the Potential of Research and Innovation in the Blue Economy to Create Jobs and Growth (2014/2240(INI).

FAO. (2014). The State of World Fisheries and Aquaculture 2014. Rome: Food and Agriculture Organization of the United Nations.

Foray, D. (2015). Smart Specialisation. Opportunities and Challenges for Regional Innovation Policy. Abingdon and New York: Routledge.

Fritz, J. S., \& Hanus, J. (2015). The European Integrated Maritime Policy: The Next Five Years. Marine Policy, 53, 1-4.

Jay, St. (2017). Issue Paper: Marine Spatial Planning, Assessing Net Benefits and Improving Effectiveness. Edited by OECD. Retrieved from https://www.oecd. org/greengrowth/GGSD_2017_Issue\%20Paper_Marine\%20Spatial\%20 Planning.pdf.

Limassol Declaration. (2012). Declaration of the European Ministers Responsible for the Integrated Maritime Policy and the European Commission, on a Marine and Maritime Agenda for Growth and Jobs, the "Limassol Declaration". Retrieved from https://ec.europa.eu/maritimeaffairs/sites/maritimeaffairs/files/docs/body/ limassol_en.pdf.

Lukic, I., Schultz-Zehden, A., Ansong, J. O., et al. (2018). Multi-Use Analysis. Edinburgh: MUSES Project.

Przedrzymirska, J., Zaucha, J., et al. (2018). Multi-use Concept in European Seabasins. Edinburgh: MUSES Project.

Schultz-Zehden, A., \& Gee, K. (2013). BaltSeaPlan Findings_Experiences and Lessons from BaltSeaPlan.

Schultz-Zehden, A., \& Gee, K. (2015). Toward Sectoral Stakeholder Involvement in a pan-Baltic MSP Dialogue. Bulletin of the Maritime Institute in Gdańsk, 30(1), 139-149.

Schultz-Zehden, A., \& Gee, K. (2016). Towards a Multi-Level Governance Framework for MSP in the Baltic. Bulletin of the Maritime Institute in Gdansk, 31(1), 34-44.

s.Pro. (2013). Study on Blue Growth, Maritime Policy and the EU Strategy for the Baltic Sea Region. Final Report FWC MARE/2012/07-Ref. No 1. (Conducted for DG Maritime Affairs and Fisheries).

s.Pro. (2017). Towards an Implementation Strategy for the Baltic Blue Growth Agenda. Commissioned by the European Commission. 
s.Pro. (2018). European MSP Platform. Retrieved June 14, 2018, from https://www. msp-platform.eu/.

s.Pro, ECORYS. (2018). Maritime Spatial Planning (MSP) for Blue Growth. Final Technical Study. Written by the European MSP Platform Under the Assistance Mechanism for the Implementation of Maritime Spatial Planning (Conducted for the Executive Agency for Small and Medium-Sized Enterprises/DG Maritime Affairs and Fisheries).

UNEP, FAO, IMO, UNDP, IUCN, World Fish Center, GRIDArendal. (2012). Green Economy in a Blue World. Retrieved from www.unep.org/greeneconomy and www.unep.org/.

Valletta Declaration. (2017). Declaration of the European Ministers Responsible for the Integrated Maritime Policy on Blue Growth, the "Valletta Declaration". Retrieved from http://data.consilium.europa.eu/doc/document/ST-8037-2017INIT/en/pdf.

Varjopuro, R., Soininen, N., Kuokkanen, T., Aps, R., Matczak, M., \& Danilova, L. (2015). Communique on the Results of the Research on Blue Growth in the Selected International Projects Aimed at Enhancement of Maritime Spatial Planning in the Baltic Sea Region (BSR). Bulletin of the Maritime Institute in Gdanisk, 30(1), 72-77.

Vergílio, M., Calado, H., \& Varona, M. C. (2017). Case Study 3B: Development of Tourism and Fishing in the Southern Atlantic Sea (Azores Archipelago-Eastern Atlantic Sea). MUSES Deliverable: D3.3—Case Study Implementation-Annex 6. MUSES Project.

World Ocean Council. (2016). Ocean Industries and Marine Planning. Retrieved from http://oceancouncil.org/wp-content/uploads/2016/05/Ocean-Industriesand-Marine-Planning_22-Mar-2016.pdf.

Open Access This chapter is licensed under the terms of the Creative Commons Attribution 4.0 International License (http://creativecommons.org/licenses/by/4.0/), which permits use, sharing, adaptation, distribution and reproduction in any medium or format, as long as you give appropriate credit to the original author(s) and the source, provide a link to the Creative Commons licence and indicate if changes were made.

The images or other third party material in this chapter are included in the chapter's Creative Commons licence, unless indicated otherwise in a credit line to the material. If material is not included in the chapter's Creative Commons licence and your intended use is not permitted by statutory regulation or exceeds the permitted use, you will need to obtain permission directly from the copyright holder.

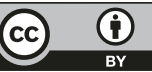

